\title{
INFEKSI SALURAN KEMIH PADA PASIEN DIABETES MELLITUS DI RSUD BUDHI ASIH JAKARTA TIMUR
}

\author{
Anastasia Hardyati \\ Program studi S1 Keperawatan Universitas MH. Thamrin \\ anastaiahardyati@gmail.com
}

\begin{abstract}
ABSTRAK
Komplikasi penyakit diabetes mellitus (DM) selain gangguan mikrovaskuler dan makrovaskuler adalah infeksi. Infeksi saluran kemih (ISK) merupakan salah satu infeksi yang paling sering terjadi pada pasien diabetes. Penelitian ini bertujuan untuk mengidentifikasi faktor yang berhubungan dengan terjadinya infeksi saluran kemih pada pasien diabetes mellitus di RSUD Budhi Asih Jakarta, dengan variabel independen yaitu jenis kelamin, usia, obesitas, lama menderita DM, dan upaya pengendalian DM. Desain penelitian yang digunakan yaitu metode deskriptif analitik dengan pendekatan Cross sectional. Metode sampling yang digunakan dalam penelitian ini adalah purposive sampling dengan jumlah 71 responden. Hasil analisa bivariat menemukan jenis kelamin ( $p$ value $=0,009$ ), usia ( $p$ value $=0.026$ ), dan upaya pengendalian diabetes mellitus ( $\mathrm{p}$ value $=0,020$ ) merupakan faktor yang berhubungan dengan terjadinya infeksi saluran kemih pada pasien diabetes mellitus. Perawat disarankan agar dapat memberikan edukasi sebagai upaya promotif dan preventif guna meminimalkan terjadinya ISK pada pasien diabetes mellitus.
\end{abstract}

Kata Kunci: Infeksi Saluran Kemih, Diabetes Mellitus, Faktor risiko

\section{PENDAHULUAN}

Prevalensi penyakit DM mengalami peningkatan di seluruh dunia. Badan kesehatan dunia atau World Health Organisation (WHO) memprediksi pada tahun 2030 diperkirakan DM menempati urutan ke-7 penyebab kematian dunia. Laporan WHO pada tahun 2012 tercatat 1,5 juta jiwa meninggal akibat penyakit diabetes (WHO, 2013). Hasil riset kesehatan dasar (Riskesdas) tahun 2013 menunjukkan bahwa prevalensi DM tertinggi terdapat di DI Yogyakarta (2,6 \%), DKI Jakarta (2,5 \%) dan Sulawesi Utara (2,4 \%) (Riskesdas, 2013).

Hasil studi pendahuluan yang dilakukan peneliti di RSUD Budhi Asih Jakarta sejak 5 bulan terakhir didapatkan data 503 orang pasien yang mengidap penyakit diabetes mellitus dan 174 orang menderita komplikasi diabetes mellitus. Data tersebut menggambarkan bahwa penderita DM dapat berisiko mengalami komplikasi dari penyakitnya. Infeksi merupakan salah satu komplikasi dari penyakit DM. Pasien DM lebih rentan menderita ISK dibandingkan dengan pasien yang tidak menderita DM. Infeksi saluran kemih pada pasien DM disebabkan oleh mikroorganisme dan didukung berbagai faktor risiko. Faktor risiko terjadinya ISK pada pasien DM antara lain umur, jenis kelamin, hubungan seksual, lama menderita DM, dan upaya pengendalian DM. Penelitian Boyko, et al.(2002) di Washington mendapatkan bahwa risiko ISK meningkat dengan bertambahnya usia pasien DM perempuan. Usia 55-75 tahun berisiko mengalami ISK terkait faktor hormonal pada kondisi postmenopause.

Penelitian yang dilakukan di Kanada mendapatkan kejadian ISK 5-20 kali lebih besar pada wanita dan secara bermakna frekuensinya lebih besar pada kehamilan dan diabetes mellitus (Nicole et al, 1996 dalam Ariwijaya, 2007). Penelitian Boyko, et al. (2002) membuktikan bahwa lama menderita DM lebih dari 10 tahun meningkatkan risiko terjadinya ISK. Lama menderita DM dihubungkan dengan pengendalian glukosa darah dan perkembangan penyakit DM. Pengendalian glukosa darah yang kurang dapat memberikan peluang terjadinya komplikasi ISK (Black \& Hawks, 2009). 
Penelitian lain yang dilakukan Soelaeman (2004) di Bandung mendapatkan adanya hubungan pengendalian glukosa darah yang kurang terhadap ISK pada pasien DM. ISK pada pasien DM umumnya terjadi pada pasien dengan pengendalian DM yang buruk dan memperberat perkembangan infeksi (Black \& Hawks, 2009).

Penderita ISK yang lebih berat akan meningkatkan risiko untuk masuk rumah sakit sebagai pielonepritis dan mempunyai frekuensi yang lebih tinggi untuk terjadinya bakterimia dan kerusakan kedua ginjal (Harding et al, 2002 dalam Saptiningsih, 2012). Selain pielonepritis, komplikasi ISK yang paling berat adalah urosepsis dengan angka kematian yang masih tinggi antara 25-60\%, dan bisa menyebabkan terjadinya gagal ginjal akut (Pranawa, 2002 dalam Ariwijaya, 2007).

Uraian diatas menggambarkan terjadi risiko peningkatan prevalensi ISK pada penderita DM dibandingkan penderita tanpa DM dan seringnya komplikasi ISK pada penderita DM, maka penelitian ini ingin mengetahui faktor-faktor yang berhubungan terhadap ISK pada penderita DM di rumah sakit sehingga hasil penelitian ini dapat digunakan untuk meningkatkan kewaspadaan untuk mencegah kejadian ISK dan komplikasi yang lebih berat pada penderita DM.

\section{METODE}

Metode penelitian yang digunakan deskriptif analitik dengan pendekatan cross sectional. Metode sampling yang digunakan adalah purposive samplingdengan jumlah 71 responden. Kriteria inklusi dalam penelitian ini yaitu pasien DM tipe 1 dan 2, kesadaran compos mentis, pasien DM yang sedang tidak hamil, pasien DM yang tidak dilakukan pemasangan catheter, kooperatif, dapat membaca dan menulis, serta bersedia menjadi responden. Pengumpulan data dilakukan pada bulan Agustus 2015 sampai dengan bulan September 2015 di RSUD Budhi Asih Jakarta. Alat pengumpulan data yang digunakan dalam penelitian ini berupa lembar kuesioner yang terdiri dari 2 bagian yaitu karakteristik responden dan penilaian faktor-faktor risiko infeksi saluran kemih. Analisis data univariat dilakukan terhadap karakteristik responden (umur, jenis kelamin, obesitas, lama menderita DM, dan upaya pengendalian DM). Analisis data bivariat menggunakan uji Chi Square.

\section{HASIL}

Analisa Univariat Hasil penelitian ini menunjukkan bahwa dari jumlah 71 responden didapatkan angka kejadian ISK pada pasien DM sebanyak 32 orang $(45,1 \%)$, distribusi jenis kelamin responden lebih besar perempuan sebanyak 46 orang $(64,8 \%)$ dibandingkan dengan laki-laki. Responden usia dewasa akhir lebih tinggi sebanyak 48 responden $(67,6 \%)$ dibandingkan dengan usia dewasa awal. Sebagian besar responden diketahui tidak mengalami obesitas sebanyak 43 responden (60,6\%). Responden yang menderita DM lebih dari 10 tahun sebanyak 42 orang $(59,2 \%)$ dan diketahui sebanyak 50 responden $(70,4 \%)$ memiliki upaya pengendalian DM yang kurang baik (Tabel 1). 
Tabel 1

Distribusi Frekuensi Variabel Dependen dan Variabel Independen di RSUD Budhi Asih Jakarta Timur $(n=71)$

\begin{tabular}{|c|c|c|}
\hline \begin{tabular}{l}
\multicolumn{1}{c}{ Variabel } \\
Variabel Dependen : \\
Kejadian Infeksi Saluran Kemih
\end{tabular} & $\mathbf{N}$ & $\%$ \\
\hline ISK & 32 & $45,154,9$ \\
\hline Tidak ISK & 39 & \\
\hline Variabel Independen : & & \\
\hline Jenis kelamin : & & \\
\hline Laki-laki & 25 & 35,2 \\
\hline Perempuan & 46 & 64,8 \\
\hline Usia : & & \\
\hline Dewasa tengah (30-50 tahun) & 23 & 32,4 \\
\hline Dewasa akhir (51-70 tahun) & 48 & 67,6 \\
\hline Obesitas : & & \\
\hline Obesitas & 28 & 39,4 \\
\hline Tidak obesitas & 43 & 60.6 \\
\hline Lama menderita DM : & & \\
\hline$<10$ tahun & 29 & 40,8 \\
\hline$\geq 10$ tahun & 42 & 59,2 \\
\hline Upaya pengendalian DM : & & \\
\hline Baik & 21 & 29,6 \\
\hline Kurang & 50 & 70,4 \\
\hline Total & 71 & 100 \\
\hline
\end{tabular}

Analisa Bivariat Hasil analisis hubungan antara jenis kelamin dengan kejadian ISK pada tabel menunjukkan bahwa sebagian besar responden perempuan mengalami ISK sebanyak 26 responden (56,5\%) dan 6 responden $(24,0 \%)$ pada responden laki-laki. Hasil uji statistik diperoleh nilai $p=0,009 \quad(\alpha \leq 0,05)$ maka dapat disimpulkan bahwa adanya hubungan yang signifikan antara jenis kelamin dengan kejadian ISK pada pasien DM. Nilai OR (Odds Ratio) $=4,117(95 \%$ CI = 1,388-12,211), artinya responden dengan jenis kelamin perempuan akan berpeluang 4,117 kali lebih besar dibandingkan laki-laki untuk terjadinya ISK pada pasien DM (Tabel 2).

Tabel 2

Hubungan Jenis Kelamin Dengan Kejadian ISK Pada Pasien DM Di RSUD Budhi Asih Jakarta Timur (n=71)

\begin{tabular}{|c|c|c|c|c|c|c|}
\hline \multirow{3}{*}{$\begin{array}{l}\text { Jenis } \\
\text { Kelamin }\end{array}$} & \multicolumn{4}{|c|}{ Terjadi ISK } & \multirow{3}{*}{$P$ Value } & \multirow{3}{*}{$\begin{array}{l}\text { OR (Odds Ratio) } 95 \% \text { CI } \\
\quad \text { (Confidence Interval) }\end{array}$} \\
\hline & \multicolumn{2}{|c|}{ Ya } & \multicolumn{2}{|c|}{ Tidak } & & \\
\hline & $\mathbf{n}$ & $\%$ & $\mathbf{N}$ & $\%$ & & \\
\hline Laki-laki & 6 & 24,0 & 19 & 76,0 & \multirow{3}{*}{0,009} & \multirow{3}{*}{$\begin{array}{c}4,117 \\
(1,388-12,211)\end{array}$} \\
\hline Perempuan & 26 & 56,5 & 20 & 43,5 & & \\
\hline Total & 32 & 45,1 & 39 & 54,9 & & \\
\hline
\end{tabular}

Hasil analisis hubungan antara usia dengan kejadian ISK pada tabel menunjukkan bahwa responden usia dewasa akhir (51-70 tahun) mengalami ISK sebanyak 26 responden $(54,2 \%)$ dan 6 responden $(26,1 \%)$ pada responden usia dewasa tengah (30-50 tahun). Hasil uji statistik diperoleh nilai $p=0,026(\alpha \leq 0,05)$ maka dapat disimpulkan bahwa adanya hubungan yang signifikan antara usia dengan kejadian ISK pada pasien DM. Nilai OR $($ Odds Ratio $)=3,348(95 \% \mathrm{CI}=1,126-9,961)$, artinya responden dengan usia dewasa akhir akan berpeluang 3,348 kali lebih besar dibandingkan usia dewasa tengah untuk terjadinya ISK pada pasien DM (Tabel 3) 
Tabel 3

Hubungan Usia Dengan Kejadian ISK Pada Pasien DM Di RSUD Budhi Asih Jakarta Timur (n=71)

\begin{tabular}{|c|c|c|c|c|c|c|}
\hline \multirow{3}{*}{ Usia } & \multicolumn{4}{|c|}{ Terjadi ISK } & \multirow{3}{*}{$P$ Value } & \multirow{3}{*}{$\begin{array}{l}\text { OR (Odds Ratio) } 95 \% \text { CI } \\
\quad(\text { Confidence Interval) }\end{array}$} \\
\hline & \multicolumn{2}{|c|}{$\mathbf{Y a}$} & \multicolumn{2}{|c|}{ Tidak } & & \\
\hline & $\mathbf{N}$ & $\%$ & $\mathbf{N}$ & $\%$ & & \\
\hline Dewasa tengah & 6 & 26,1 & 17 & 73,9 & \multirow{3}{*}{0.026} & \multirow{3}{*}{$\begin{array}{c}3,348 \\
(1,126-9,961)\end{array}$} \\
\hline Dewasa akhir & 26 & 54,2 & 22 & 45,8 & & \\
\hline Total & 32 & 45,1 & 39 & 54,9 & & \\
\hline
\end{tabular}

Hasil analisis hubungan antara upaya pengendalian DM dengan kejadian ISK sebanyak 27 responden (54,0\%) memiliki pengendalian DM yang kurang baik mengalami ISK sedangkan responden yang memilki pengendalian DM yang baik sebanyak 5 orang $(23,8 \%)$. Hasil uji statistik diperoleh nilai $p=0,020(\alpha \leq 0,05)$ maka dapat disimpulkan bahwa adanya hubungan yang kuat antara upaya pengendalian DM dengan kejadian ISK pada pasien DM. Nilai OR (Odds Ratio) $=3,757(95 \%$ CI $=1,192-11,839)$, artinya responden dengan upaya pengendalian DM yang kurang baik akan berpeluang 3,757 kali lebih besar untuk terjadinya ISK pada pasien DM dibandingkan responden dengan upaya pengendalian DM yang baik (Tabel 4).

Tabel 4

Hubungan Upaya Pengendalian DM Dengan Kejadian ISK Di RSUD Budhi Asih Jakarta Timur (n=71)

\begin{tabular}{|c|c|c|c|c|c|c|}
\hline \multirow{3}{*}{$\begin{array}{l}\text { Upaya Pengendalian } \\
\text { DM }\end{array}$} & \multicolumn{4}{|c|}{ Terjadi ISK } & \multirow{3}{*}{$P$ Value } & \multirow{3}{*}{$\begin{array}{l}\text { OR (Odds Ratio) } 95 \% \text { CI } \\
\quad \text { (Confidence Interval) }\end{array}$} \\
\hline & \multicolumn{2}{|c|}{ Ya } & \multicolumn{2}{|c|}{ Tidak } & & \\
\hline & $\mathbf{N}$ & $\%$ & $\mathbf{N}$ & $\%$ & & \\
\hline Baik & 5 & 23,8 & 16 & 76,2 & \multirow{3}{*}{0,020} & \multirow{3}{*}{$\begin{array}{c}3,757 \\
(1,192-11,839)\end{array}$} \\
\hline Kurang & 27 & 54,0 & 23 & 46,0 & & \\
\hline Total & 32 & 45,1 & 39 & 54,9 & & \\
\hline
\end{tabular}

\section{PEMBAHASAN}

\section{Hubungan Jenis Kelamin Dengan Kejadian ISK Pada Pasien DM}

Hasil analisis hubungan antara jenis kelamin dengan kejadian ISK pada pasien DM menunjukkan bahwa sebagian besar responden berjenis kelamin perempuan sebanyak 26 responden $(56,5 \%)$ yang mengalami terjadinya ISK. Penelitian ini menunjukkan bahwa jenis kelamin dengan kejadian ISK pada pasien DM memiliki $p$ value $=0,009$ yang artinya ada hubungan antara jenis kelamin dengan kejadian ISK pada pasien DM dan responden dengan jenis kelamin perempuan akan berpeluang 4 kali lebih besar untuk terjadinya ISK pada pasien DM. Hasil penelitian ini menunjukkan bahwa mayoritas kasus infeksi saluran kemih didominasi oleh wanita. Penelitian yang dilakukan oleh Hirji et al (2012) di Kanada sejalan dengan hasil penelitian ini yang menyatakan bahwa prevalensi wanita lebih berisiko mengalami ISK bila dibandingkan dengan pria. Penelitian lain yang dilakukan oleh Ariwijaya (2007) mengemukakan bahwa prevalensi infeksi saluran kemih pada pasien DM wanita 40,4 \% dan laki-laki 32,1\%. Hal ini disebabkan karena wanita memiliki uretra yang pendek, secara anatomi dekat dengan vagina, kelenjar periuretral dan rektum. Uretra yang pendek memudahkan bakteri kontaminan memperoleh akses ke kandung kemih dan meningkatkan terjadinya ISK. Kecenderungan budaya untuk menahan urine juga dapat meningkatkan risiko pertumbuhan bakteri (Corwin, 2009). 


\section{Hubungan Usia Dengan Kejadian ISK Pada Pasien DM}

Hasil analisis hubungan antara usia dengan kejadian ISK menunjukkan bahwa usia dewasa akhir (51-70 tahun) mengalami ISK sebanyak 26 responden(54,2\%). Hasil analisis diperoleh nilai $p=0,026$ yang artinya ada hubungan yang signifikan antara usia dengan kejadian ISK pada pasien DM dan responden dengan usia dewasa akhir akan berpeluang 3 kali lebih besar untuk terjadinya ISK pada pasien DM. Proses degenerasi pada usia lanjut menyebabkan terjadinya penurunan kapasitas kandung kemih dan meningkatnya kontraksi kandung kemih yang dapat meningkatkan urgency dan frequency. Abnormalitas struktur pada penuaan dan kandung kemih neurogenik akibat neuropati otonom pada diabetes juga menyebabkan peningkatan risiko terjadinya ISK (Meiner \& Lueckenotte, 2006 dalam Saptiningsih, 2012, Smeltzer \& Bare, 2002).

Penelitian Hirji et al (2012) sejalan dengan hasil penelitian ini yang menunjukkan bahwa usia $\geq 50$ tahun lebih banyak mengalami ISK dibandingkan usia $<50$ tahun yang mengalami ISK. Penelitian lain yang dilakukan oleh Boyko et al (2002) mendukung hasil penelitian ini bahwa wanita usia 55-75 tahun beresiko mengalami ISK terkait faktor hormonal pada kondisi pasca menopausal. Wanita pasca menopausal rentan terhadap kolonisasi dan perlekatan bakteri pada vagina dan uretra akibat tidak adanya esterogen. Perubahan-perubahan tersebut menjadi faktor risiko yang akan meningkatkan terjadinya infeksi saluran kemih (Smeltzer \& Bare, 2002, Corwin, 2009, Lewis et al, 2007).

\section{Hubungan Upaya Pengendalian DM Dengan Kejadian ISK Pada Pasien DM}

Hasil analisis hubungan antara upaya pengendalian DM dengan kejadian ISK pada pasien DM sebanyak27 responden $(52,1 \%)$ memiliki pengendalian DM yang kurang baik mengalami ISK. Hasil uji statistik diperoleh nilai $p=0,005$ maka dapat diartikan bahwa ada hubungan antara upaya pengendalian DM dengan kejadian ISK pada pasien DM dan responden dengan upaya pengendalian DM yang kurang baik akan berpeluang 3 kali lebih besar untuk terjadinya ISK pada pasien DM.

Hasil penelitian ini sejalan dengan penelitian yang dilakukan Soeleman (2004) tentang hubungan pengendalian glukosa darah yang buruk dengan terjadinya infeksi saluran kemih. Penelitian lain yang dilakukan oleh Saptingsih (2012) tentang determinan infeksi saluran kemih pasien diabetes mellitus perempuan yang menunjukkan ada hubungan antara upaya pengendalian DM terhadap kejadian ISK pada pasien DM. Pengendalian glukosa darah yang kurang tepat dapat memberikan peluang terjadinya komplikasi ISK. (PERKENI, 2011).

\section{KESIMPULAN DAN REKOMENDASI}

Kesimpulan penelitian ini yaitu Faktor risiko yang berhubungan terjadinya ISK pada pasien DM adalah jenis kelamin ( $p=0,009)$, usia $(p=0.026)$, dan upaya pengendalian DM ( $p=0,020)$.

Rekomendasi yang peneliti berikan yaitu pelayanan di rumah sakit sebaiknya lebih memaksimalkan pelayanan kesehatan dengan cara menambahkan program khusus untuk pasien DM dan perawat diharapkan melakukan pengkajian lebih dalam mengenai faktor risiko ISK pada pasien DM serta memotivasi pasien untuk terus melakukan upaya pengendalian gula darah. Bagi pasien DM sendiri diharapkan dapat lebih patuh dalam upaya mengendalikan DM agar mencegah terjadinya komplikasi DM lebih lanjut seperti infeksi saluran kemih 


\section{REFERENSI}

1. Ariwijaya, M. \& Suwitra, K (2007). Prevalensi, karakteristik dan faktor-faktor yang terkait dengan infeksi saluran kemih pada penderita diabetes melitus yang rawat inap. Jurnal Penyakit Dalam, 8(2), 112-127.

2. Badan Penelitian dan Pengembangan Kesehatan Departemen Kesehatan, Republik Indonesia. (2013). Riset kesehatan dasar 2013. Laporan Nasional 2013. Jakarta.

3. Black, J.M. \& Hawks, J.H. (2009). Medical-surgical nursing Clinical Management for positive outcomes Eighth edition. St. Louis : Saunders, an imprint of Elsevier, Inc.

4. Boyko, Edward J., Fihn Stephan D., Scholes Delia, Chi-Ling, Chen; et al. (2002). Diabetes and the Risk of a Acute Urinary Tract Infection Among Postmenopausal Woman.Diabetes Care, 25(10). ProQuest Nursing \& Allied Health Source pg. 1778.

5. Corwin, Elizabeth J. (2009). Buku Saku Patofisiologi, alih bahasa, Nike Budhi Subekti, editor Egi komara Yudha, dkk Ed. 3. Jakarta : EGC.

6. Guyton, A.C. \& Hall, J.E. (2008). Buku ajar fisiologi kedokteran. Alih bahasa: Irawati, dkk. Editor: Yanuar Rachman, dkk. Edisi 11. Cetakan I. Jakarta : EGC.

7. Hirji, Ishan; Guo, Zhenchao; Andersson, Susan W.; Hammar, Niklas; Gomez-Caminero, Andres. (2012). Incidence of urinary tract infection among patients with type 2 diabetes in the UK General Practice Research Database (GPRD). Journal of Diabetes and its Complications26(6). ProQuest Nursing \& Allied Health Source pg. 513-516

8. IDF. (2013). IDF Diabetes Atlas Sixth Edition, International Diabetes Federation 2013.http://www.idf.org/sites/default/files/EN_6E_Atlas_Full_0.pdf diakses tanggal 29 Juni 2015.

9. Lewis, S.L., Heitkemper, M.M., Dirksen, S.R., O’Brien, P.G., Bucher, L. (2007). Medical-surgical nursing. Assessment and management of clinical problems. Volume 2. St. Louis: Mosby, Inc., an affiliate of Elsevier Inc.

10. Perkumpulan Endokrinologi Indonesia. (2011). Konsensus pengelolaan dan pencegahan diabetes melitus tipe 2 di Indonesia. Jakarta : PB PERKENI.

11. Saptiningsih, Monica. (2012). Determinan Infeksi Saluran Kemih Pasien Diabetes Melitus Perempuan. Tesis. Diperoleh pada tanggal 16 Juni 2015 dari http://lib.ui.ac.id/file?file=digital/20303830.pdf.

12. Smeltzer, S.C \&Bare, B.G.(2002).Buku Ajar Medikal Bedah Edisi 8 Volume 2, Alih Bahasa Kuncara, H.Y, dkk. Jakarta : EGC.

13. Soelaeman, R. (2004). Pengobatan terkini infeksi saluran kemih. The $4^{\text {th }}$ Jakarta Nephrology \& Hypertension Course and Symposium of Hypertension. Jakarta : PERNEFRI

14. WHO. (2013). http://www.who.int/mediacentre/factsheets/fs312/en/ diakses tanggal 20 Januari 2014 